\title{
Primary immunodeficiency diseases in lung disease: warning signs, diagnosis and management
}

\author{
Pere Soler-Palacín ${ }^{1 *}$ D, Javier de Gracia ${ }^{1,6}$, Luis Ignacio González-Granado², Carlos Martín², \\ Carlos Rodríguez-Gallego ${ }^{4}$, Silvia Sánchez-Ramón ${ }^{5}$ and Lung ID-Signal Group
}

\begin{abstract}
Background: Pulmonary complications are common in primary immunodeficiency diseases (PID) and contribute to morbidity and mortality in these patients. However, their varied presentation and a general lack of awareness of PID in this setting make early diagnosis and treatment difficult. The aim of this study was to define the warning signs of PID in patients with respiratory manifestations, the necessary diagnostic tests, and the therapeutic management of both children and adults.

Methods: A review of the literature was performed, and 43 PID interdisciplinary specialists were consulted.

Results: This document identifies the pulmonary and extrapulmonary manifestations that should prompt a suspicion of PID, the immunological and respiratory tests that should be included in the diagnostic process according to the level of care, recommendations regarding the use of immunoglobulin replacement therapy according to the specific immunodeficiency, and the minimum recommended immunological and pulmonary monitoring in these patients.

Conclusions: This document is the first to combine scientific evidence with the opinion of a broad panel of experts specializing in the treatment of patients with immunodeficiencies. It aims to provide a useful tool for all practitioners who are regularly involved in the management of these patients.
\end{abstract}

Keywords: "Immunoglobulins/deficiency"[mesh], "Antibodies/deficiency"[mesh], "Immunoglobulins/administration and dosage"[mesh], "Respiratory Tract Infections"[mesh], "Immunologic Deficiency Syndromes"[mesh]

\section{Background}

Immunodeficiency diseases (ID) are disorders involving a quantitative and/or functional disorder in the immune response [1] that may lead to a greater risk of infections, immune dysregulation, autoimmune phenomena, inflammation, and cancer. These IDs are classified as primary immunodeficiency diseases (PIDs) if their origin is genetic, and secondary (SID) if acquired.

PIDs comprise a heterogeneous group of more than 300 diseases. The Primary Immunodeficiencies Classification Committee of the International Union of Immunological Societies (IUIS) divides PIDs into 8 groups (9, if we include PID phenocopies), depending on their clinical and

\footnotetext{
*Correspondence: psoler@vhebron.net

${ }^{1}$ Hospital U. Vall d'Hebron, P. de la Vall d'Hebron, 119-129, 08035 Barcelona, Spain

Full list of author information is available at the end of the article
}

immunological phenotype [2]. The various congenital or acquired defects can affect both the innate and the acquired immune system [3]. The most common PIDs are predominantly antibody disorders (56.66\%), other well defined PIDs (13.91\%), phagocytic disorders $(8.73 \%)$, predominantly $\mathrm{T}$ cell deficiencies $(7.47 \%)$, and complement deficiencies (4.89\%) [4].

The prevalence of PID in Europe and the United States ranges from 41 to 83 per 100,000 inhabitants, depending on the study $[5,6]$. The diagnosis of PID often emerges from a picture of recurrent or unusual infections, autoimmune diseases, inflammatory processes or cancers. A careful approach must be taken in the early detection of these signs, in order to avoid unnecessary testing, but without delaying diagnosis. However, since their clinical presentation varies widely and understanding of this area is often limited, underdiagnosis and

(c) The Author(s). 2018 Open Access This article is distributed under the terms of the Creative Commons Attribution 4.0 International License (http://creativecommons.org/licenses/by/4.0/), which permits unrestricted use, distribution, and 
delayed diagnosis are common, generating significant morbidity and mortality [7] and a major social and economic impact [8]. Generally, the early clinical manifestations of PID occur during childhood, but they also are frequently encountered in the second or third decade of life, or even in older patients [9]. Moreover, there are different clinical presentations across various age categories and these presentations in children could widely differ from adult patients with PID [10].

New warning signs alerting to a suspicion of PID are being increasingly described, based on clinical presentations - mainly infectious diseases - and, in some cases, family history. Fifteen years ago, the Jeffrey Modell Foundation (JMF) defined the warning signs of suspected PID in children and adults $[8,11]$. This document is a useful basis, but one that needs to be updated, as it does not refer to the autoimmune, inflammatory or malignant manifestations of PIDs, which can be the main clinical presentation in some of these diseases [12]. In addition, a follow-up study by Subbarayan et at highlighted the low sensitivity and specificity of these warning signs, recommending that PID awareness initiatives should be mainly targeted at hospital pediatricians and families with a history of PID although these initiatives should also include the general public [13].

Pulmonary complications in PID are common and significantly contribute to the morbidity and mortality of patients. Recurrent respiratory tract infections often constitute the first warning sign in some PIDs and are often the main cause of death in adults with PID [14, $15]$.

The aim of this study was to define which warning signs should alert to the suspicion of PID in patients with respiratory manifestations, and to develop proposals for intervention in these cases. This document is aimed at primary care (PC) professionals and specialists who see both adult and pediatric patients with respiratory diseases. This study is part of the ID-Signal Project, which aims to generate a series of documents based on the clinical manifestations of IDs dedicated to non-immunologists who may take care of patients with PID or SID in their clinical practice.

\section{Methods}

Initially, an interdisciplinary expert group formed of 2 pulmonologists, 2 immunologists and 2 pediatricians specializing in immunodeficiencies identified items to be addressed in the areas of clinical and laboratory testing, diagnostic imaging, functional tests, and therapeutic approach, and prepared a series of recommendations. A review of the literature was then performed, which acted as a basis for a discussion of the contents of the document in an in-person meeting. The main conclusions and recommendations were forwarded to an external panel of experts for their individual evaluation, depending on their specialty. Although we could have done a Delphi process involving at least two rounds, we preferred a single consultation to have a general view of the opinion of a larger group of experts and to make the process easier. The external panel consisted of 43 experts from all over Spain, with experience in the diagnosis and treatment of PID, working in Spanish National Health System centers. In total, 19 immunologists specializing in adults (adult immunologists, AI), 15 pediatric specialists in immunodeficiencies (pediatric immunologists, PI), 5 pulmonologists taking care of adults (adult pulmonologists, AP), and 4 pediatric specialists in pulmonology (pediatric pulmonologists, PP) participated.

This panel indicated their level of agreement on a scale of 1 to 4 , with 1 reflecting "strongly disagree" and 4 "strongly agree", and they could also add comments when necessary. The results were pooled and the percentages of votes in the categories 1 and 2 (disagree) and in the categories 3 and 4 (agreement) were calculated. Unanimity was determined when $100 \%$ of the experts agreed with recommendation/conclusion; consensus, when at least $80 \%$ of the experts agreed without unanimity; majority, when more than $65 \%$ and less than $80 \%$ of the experts agreed with the recommendation/conclusion; and disagreement, when the percentage of agreement was $65 \%$ or less.

\section{Results and discussion}

\section{Lung diseases that should prompt a suspicion of PID}

In general, lung complications caused by PID include respiratory tract infections, interstitial lung disease (ILD), and cancers [14]. Recurrent lung infections are often the first warning sign in both adult and pediatric PID patients. These recurrent infections often cause permanent lung damage if appropriate treatment is not promptly initiated. Usually, there are also frequent upper respiratory infections previous to the lower ones, so an optimal pulmonary management should encompass the upper airway [16]. Airway damage can manifest as air trapping, thickening of the bronchial walls, atelectasis and/or bronchiectasis [14, 17]. The pathogens most commonly associated with pneumonia in patients with ID will depend on the type of immunodeficiency presented by the patient but generally include Streptococcus pneumoniae and Haemophilus influenzae, followed by Mycoplasma spp., Staphylococcus spp., Moraxella spp., Pseudomonas aeruginosa, and other viral pathogens, and more rarely Pneumocystis jirovecii and various fungi [18].

However, since mortality due to infectious complications has declined, non-infectious complications have begun to account for a large number of the poor clinical outcomes observed in some of these patients [19]. Thus, several histological patterns of ILD have been identified 
in patients with PID, especially in those with a diagnosis of common variable immunodeficiency disease (CVID), including granulomatous lung disease, lymphoid interstitial pneumonia (LIP), non-specific interstitial pneumonia (NSIP), and organizing pneumonia, and more than one may co-exist in the same patient [14].

The patient profile (adult or pediatric) and pulmonary manifestations (infectious or non-infectious) that lead to a consultation in $\mathrm{PC}$ or with a respiratory medicine specialist may be different. Manifestations that should prompt a suspicion of PID are included in Table 1. A respiratory medicine specialist must ensure that pneumonia is confirmed on radiology: this will be suggestive of PID, particularly if disease appears in different sites. Cases of slow-progressing disease must be investigated, and pneumonias that do not resolve with multiple course of antibiotics and require hospital admission, intravenous antibiotics or intensive care assistance, should be noted, along with a high frequency of pneumonias across time (one pneumonia per year for more than one year). Slow-progressing pneumonitis or bronchitis in an infant that requires admission, particularly in the intensive care unit, should be considered as potential

Table 1 Respiratory manifestations indicating a suspicion of PID in primary care and pulmonology clinics

\begin{tabular}{|c|c|c|c|}
\hline Respiratory Manifestions with suspicion of PID in PC & N (Composition of panel) & $\begin{array}{l}\text { Votes in agreement } \\
\text { (\%) }\end{array}$ & $\begin{array}{l}\text { Degree of } \\
\text { agreement }\end{array}$ \\
\hline \multicolumn{4}{|l|}{ Adult patient } \\
\hline $\begin{array}{l}\text { Recurrent bronchial infections ( } \geq 2 / \text { year), with cough and purulent } \\
\text { expectoration }\end{array}$ & $23^{*}(\mathrm{Al}, \mathrm{AP})$ & 87.0 & Consensus \\
\hline Idiopathic bronchiectasis & $23^{*}(\mathrm{Al}, \mathrm{AP})$ & 100.0 & Unanimity \\
\hline Recurrent pneumonias** & $23^{*}(\mathrm{Al}, \mathrm{AP})$ & 100.0 & Unanimity \\
\hline Chronic bronchial infection & $23^{*}(\mathrm{Al}, \mathrm{AP})$ & 91.3 & Consensus \\
\hline Need for prolonged antibiotic treatment for respiratory infections & $23^{*}(\mathrm{Al}, \mathrm{AP})$ & 95.7 & Consensus \\
\hline \multicolumn{4}{|l|}{ Pediatric patient } \\
\hline Recurrent pneumonias** & $19(\mathrm{PI}, \mathrm{PP})$ & 100.0 & Unanimity \\
\hline Idiopathic bronchiectasis & 19 (PI, PP) & 100.0 & Unanimity \\
\hline Respiratory manifestations with suspicion of PID in pulmonolgy unit & N (Composition panel) & $\begin{array}{l}\text { Votes in agreement } \\
(\%)\end{array}$ & $\begin{array}{l}\text { Degree of } \\
\text { agreement }\end{array}$ \\
\hline \multicolumn{4}{|l|}{ Infections } \\
\hline \multicolumn{4}{|l|}{ Adult and pediatric patients } \\
\hline $\begin{array}{l}\text { Recurrent bronchial infections ( } \geq 2 / \text { year), with cough and purulent } \\
\text { expectoration }\end{array}$ & $43(\mathrm{Al}, \mathrm{AP}, \mathrm{Pl}, \mathrm{PP})$ & 86.0 & Consensus \\
\hline Idiopathic bronchiectasis & $43(\mathrm{Al}, \mathrm{AP}, \mathrm{Pl}, \mathrm{PP})$ & 100.0 & Unanimity \\
\hline Recurrent pneumonias** & $43(\mathrm{Al}, \mathrm{AP}, \mathrm{Pl}, \mathrm{PP})$ & 97.7 & Consensus \\
\hline Chronic bronchial infection & $43(\mathrm{Al}, \mathrm{AP}, \mathrm{Pl}, \mathrm{PP})$ & 90.7 & Consensus \\
\hline Need for prolonged antibiotic treatment for respiratory infections & $43(\mathrm{Al}, \mathrm{AP}, \mathrm{Pl}, \mathrm{PP})$ & 93.0 & Consensus \\
\hline Pulmonary abscess and pneumatocele & $43(\mathrm{Al}, \mathrm{AP}, \mathrm{Pl}, \mathrm{PP})$ & 90.7 & Consensus \\
\hline Infections caused by rare or opportunistic microorganisms & $43(\mathrm{Al}, \mathrm{AP}, \mathrm{Pl}, \mathrm{PP})$ & 100.0 & Unanimity \\
\hline \multicolumn{4}{|l|}{ Infants } \\
\hline Severe infantile bronchiolitis or pneumonia & $43(\mathrm{Al}, \mathrm{AP}, \mathrm{Pl}, \mathrm{PP})$ & 93.0 & Consensus \\
\hline \multicolumn{4}{|l|}{ NON-INFECTIOUS } \\
\hline \multicolumn{4}{|l|}{ Adult and pediatric patients } \\
\hline Granulomatous-lymphocytic interstitial lung disease & $43(\mathrm{Al}, \mathrm{AP}, \mathrm{Pl}, \mathrm{PP})$ & 100.0 & Unanimity \\
\hline Bronchiolitis obliterans & $43(\mathrm{Al}, \mathrm{AP}, \mathrm{Pl}, \mathrm{PP})$ & 72.1 & Majority \\
\hline Lymphoproliferative syndrome & $43(\mathrm{Al}, \mathrm{AP}, \mathrm{Pl}, \mathrm{PP})$ & 90.7 & Consensus \\
\hline Alveolar proteinosis & $43(\mathrm{Al}, \mathrm{AP}, \mathrm{Pl}, \mathrm{PP})$ & 86.0 & Consensus \\
\hline Recurrent serositis & $43(\mathrm{Al}, \mathrm{AP}, \mathrm{PI}, \mathrm{PP})$ & 76.7 & Majority \\
\hline Thymic disorders: thymoma (adult), thymic aplasia (infant) & $43(\mathrm{Al}, \mathrm{AP}, \mathrm{Pl}, \mathrm{PP})$ & 100.0 & Unanimity \\
\hline
\end{tabular}

Al: adult immunologists; AP: adult pulmonologists; PC: primary care; PI: pediatric immunologists; PID: primary immunodeficiency disease; PP: pediatric pulmonologists

*One value is missing. ** One pneumonia per year for more than one year 
manifestations of PID, although severe bronchiolitis may be relatively common in healthy infants.

\section{Classification of respiratory diseases by PID type}

PIDs have been divided into several categories, according to their clinical characteristics and immune system involvement. In any case, we must remember that inclusion in one category or another involves an important academic component, and in routine practice, the clinical context of the patient will help guide their classification. There are some lung manifestations that should lead to the suspicion of a specific PID. This is the case of pneumatocele and AD-hyperIgE syndrome, bronchiectasis and antibody deficiencies, severe bronchiolitis and severe combined immunodeficiencies or pulmonary fungal infections and phagocyte disorders, among others. However, most lung diseases can occur in a wide range of PID, in which a wide but phased diagnostic protocol is recommended.

Table 2 identifies the respiratory pathogens that are most commonly associated with each type of PID; several manifestations only achieved a majority agreement but not consensus, possibly due to the limited experience available in certain types of manifestations. Discrepancies were found for other manifestations ("abscess and pneumatocele" and "bronchiolitis obliterans", with agreements of 55.8 and $60.5 \%$, respectively).

Table 2.

\section{EXTRAPULMONARY manifestations that should suggest PID}

It is very important that the specialist who evaluates a patient with suspected PID due to lung problems also takes in account the presence of extrapulmonary manifestations that might support the clinical suspicion of PID, since one of the main characteristics of PID is its ability to affect multiple organs or systems simultaneously or sequentially. PID may present with skin [20-22], gastrointestinal [23], or autoimmune [24-26] manifestations, among others. Table 3 (adapted from JC Aldave [27]) lists the main extrapulmonary clinical manifestations, with their degrees of agreement. Two common extrapulmonary manifestations did not reach consensus.

On the other hand, there are some histopatological findings which would prompt the clinician to consider a diagnosis of PID before having the suspicious of it. This is the case of granulomas or the absence of plasma cells in a gastrointestinal biopsy.

\section{Diagnostic tests to be performed in patients with suspected PID}

A large number of PIDs can be diagnosed from a detailed clinical history that includes a family history of PID, consanguinity, or family members who died at a young age, a comprehensive physical examination, blood tests, and a determination of serum immunoglobulin (Ig) levels. These tests are available in the vast majority of laboratories, even in PC. The physical examination should be detailed and ordered by body system, and it is important to assess the patient's nutritional status, with particular attention to height and weight and sequelae from previous infections. The presence of lymphadenopathies or the absence of nodal chains, tonsils, hepatosplenomegaly, etc. must be determined, since in some cases these parameters may orient the professional towards a specific PID. A complete blood count (CBC) with a differential count provides important information on suspected cytopenias (neutropenia, monocytopenia, lymphopenia, or thrombocytopenia) and qualitative cellular changes [9]. The determination of serum Igs (IgG, $\operatorname{IgM}$, IgA, and IgE) is the first step in the evaluation of humoral immunity, and will help diagnose or at least point to a suspicion of quantitative Ig deficiencies, such as congenital agammaglobulinemia, CVID, or selective IgA deficiency, and humoral changes associated with other defects, such as hyper-IgE or hyper-IgM syndrome [9]. On the other side, quantification of calculated globulin (CG, total protein minus albumin [28]), T-cell recombination excision circles (TREC) and kappa-deleting element recombination circles (KREC) may help identify PIDs early in PC. Recently, a study by Pecoraro et al showed that a screening calculated globulin test could be used as a tool to reduce diagnostic delays, improve long-term prognosis and reduce the healthcare costs of antibody deficiency [29].

There are obvious differences between diagnosis in children and adults since, usually, most severe PID are diagnosed in childhood while recurrent respiratory infections, which can be caused by many other non-immunological entities and are the clue for the diagnosis during adulthood. Adolescents are a special population with mixed manifestations. Therefore, first line diagnostic tests in adults are almost specifically based on ruling primary antibody deficiency out (immunoglobulin levels and antibody production assessment), while clinical manifestations will orient the initial tests in childhood (e.g. burst oxidation tests in invasive fungal infections, complement pathway assessment if recurrent bacteremia...).

It is important to assess the results according to the reference values for each age, since there are significant differences which, if not taken into account, can cause PID to be overlooked [30]. In addition, it is always important that the suspected diagnosis is oriented to avoiding unnecessary studies that result in a waste of time and resources. However, when the diagnosis is uncertain and suspicion is high, additional tests, such as functional or molecular studies, are needed, and these must be conducted in reference centers. In fact, some of the 
Table 2 Common respiratory manifestations by PID type

\begin{tabular}{|c|c|c|c|}
\hline Common respiratory manifestations by PID type & N (Composition of panel) & Votes in agreement (\%) & Degree of agreement \\
\hline \multicolumn{4}{|c|}{ Predominantly T cell deficiency (combined and PID-related syndromes) } \\
\hline Recurrent bronchitis & $43(\mathrm{Al}, \mathrm{AP}, \mathrm{Pl}, \mathrm{PP})$ & 72.1 & Majority \\
\hline Idiopathic bronchiectasis & $43(\mathrm{Al}, \mathrm{AP}, \mathrm{Pl}, \mathrm{PP})$ & 76.7 & Majority \\
\hline Recurrent pneumonias* & $43(\mathrm{Al}, \mathrm{AP}, \mathrm{Pl}, \mathrm{PP})$ & 88.4 & Consensus \\
\hline Repeated pneumonia in child & $43(\mathrm{Al}, \mathrm{AP}, \mathrm{Pl}, \mathrm{PP})$ & 88.4 & Consensus \\
\hline Chronic bronchial infection & $43(\mathrm{Al}, \mathrm{AP}, \mathrm{Pl}, \mathrm{PP})$ & 79.1 & Majority \\
\hline Prolonged antibiotic treatment with poor response & $43(\mathrm{Al}, \mathrm{AP}, \mathrm{Pl}, \mathrm{PP})$ & 86.0 & Consensus \\
\hline Abscess and pneumatocele & $43(\mathrm{Al}, \mathrm{AP}, \mathrm{Pl}, \mathrm{PP})$ & 55.8 & Discrepancy \\
\hline Infections caused by rare microorganisms & $43(\mathrm{Al}, \mathrm{AP}, \mathrm{Pl}, \mathrm{PP})$ & 100.0 & Unanimity \\
\hline Pneumonitis or bronchitis with hospitalization in infants & $43(\mathrm{Al}, \mathrm{AP}, \mathrm{Pl}, \mathrm{PP})$ & 86.0 & Consensus \\
\hline Interstitial lung disease & $43(\mathrm{Al}, \mathrm{AP}, \mathrm{Pl}, \mathrm{PP})$ & 93.0 & Consensus \\
\hline Bronchiolitis obliterans & $43(\mathrm{Al}, \mathrm{AP}, \mathrm{Pl}, \mathrm{PP})$ & 67.4 & Majority \\
\hline Alveolar proteinosis & $43(\mathrm{Al}, \mathrm{AP}, \mathrm{Pl}, \mathrm{PP})$ & 76.7 & Majority \\
\hline Absent thymus or aplasia & $43(\mathrm{Al}, \mathrm{AP}, \mathrm{Pl}, \mathrm{PP})$ & 95.3 & Consensus \\
\hline \multicolumn{4}{|l|}{ Antibody deficiencies } \\
\hline Recurrent bronchitis & $43(\mathrm{Al}, \mathrm{AP}, \mathrm{Pl}, \mathrm{PP})$ & 90.7 & Consensus \\
\hline Idiopathic bronchiectasis & $43(\mathrm{Al}, \mathrm{AP}, \mathrm{Pl}, \mathrm{PP})$ & 97.7 & Consensus \\
\hline Recurrent pneumonias* & $43(\mathrm{Al}, \mathrm{AP}, \mathrm{Pl}, \mathrm{PP})$ & 97.7 & Consensus \\
\hline Repeated pneumonia in child & $43(\mathrm{Al}, \mathrm{AP}, \mathrm{Pl}, \mathrm{PP})$ & 97.7 & Consensus \\
\hline Chronic bronchial infection & $43(\mathrm{Al}, \mathrm{AP}, \mathrm{Pl}, \mathrm{PP})$ & 90.7 & Consensus \\
\hline Prolonged antibiotic treatment with poor response & $43(\mathrm{Al}, \mathrm{AP}, \mathrm{Pl}, \mathrm{PP})$ & 97.7 & Consensus \\
\hline Pneumonia due to encapsulated bacteria & $43(\mathrm{Al}, \mathrm{AP}, \mathrm{Pl}, \mathrm{PP})$ & 97.7 & Consensus \\
\hline Interstitial lung disease & $43(\mathrm{Al}, \mathrm{AP}, \mathrm{Pl}, \mathrm{PP})$ & 79.1 & Majority \\
\hline Bronchiolitis obliterans & $43(\mathrm{Al}, \mathrm{AP}, \mathrm{Pl}, \mathrm{PP})$ & 60.5 & Discrepancy \\
\hline Pulmonary lymphoma & $43(\mathrm{Al}, \mathrm{AP}, \mathrm{Pl}, \mathrm{PP})$ & 69.8 & Majority \\
\hline Thymoma & $43(\mathrm{Al}, \mathrm{AP}, \mathrm{Pl}, \mathrm{PP})$ & 88.4 & Consensus \\
\hline \multicolumn{4}{|l|}{ Immune deregulation } \\
\hline Recurrent bronchitis & $43(\mathrm{Al}, \mathrm{AP}, \mathrm{Pl}, \mathrm{PP})$ & 69.8 & Majority \\
\hline Idiopathic bronchiectasis & $43(\mathrm{Al}, \mathrm{AP}, \mathrm{Pl}, \mathrm{PP})$ & 74.4 & Majority \\
\hline Chronic bronchial infection & $43(\mathrm{Al}, \mathrm{AP}, \mathrm{Pl}, \mathrm{PP})$ & 65.1 & Majority \\
\hline Pneumonia due to encapsulated bacteria & $43(\mathrm{Al}, \mathrm{AP}, \mathrm{Pl}, \mathrm{PP})$ & 67.4 & Majority \\
\hline Interstitial lung disease & $43(\mathrm{Al}, \mathrm{AP}, \mathrm{Pl}, \mathrm{PP})$ & 81.4 & Consensus \\
\hline \multicolumn{4}{|l|}{ Phagocyte disorders } \\
\hline Recurrent pneumonias* & $43(\mathrm{Al}, \mathrm{AP}, \mathrm{Pl}, \mathrm{PP})$ & 90.7 & Consensus \\
\hline Prolonged antibiotic treatment with poor response & $43(\mathrm{Al}, \mathrm{AP}, \mathrm{Pl}, \mathrm{PP})$ & 88.4 & Consensus \\
\hline Abscess and pneumatocele & $43(\mathrm{Al}, \mathrm{AP}, \mathrm{Pl}, \mathrm{PP})$ & 97.7 & Consensus \\
\hline Infections caused by rare microorganisms & $43(\mathrm{Al}, \mathrm{AP}, \mathrm{Pl}, \mathrm{PP})$ & 97.7 & Consensus \\
\hline Alveolar proteinosis & $43(\mathrm{Al}, \mathrm{AP}, \mathrm{Pl}, \mathrm{PP})$ & 69.8 & Majority \\
\hline \multicolumn{4}{|l|}{ Innate immunity disorder } \\
\hline Recurrent pneumonias* & $43(\mathrm{Al}, \mathrm{AP}, \mathrm{Pl}, \mathrm{PP})$ & 97.7 & Consensus \\
\hline Pneumonia due to encapsulated bacteria & $43(\mathrm{Al}, \mathrm{AP}, \mathrm{Pl}, \mathrm{PP})$ & 95.3 & Consensus \\
\hline Abscess and pneumatocele & $43(\mathrm{Al}, \mathrm{AP}, \mathrm{Pl}, \mathrm{PP})$ & 83.7 & Consensus \\
\hline Infections caused by rare microorganisms & $43(\mathrm{Al}, \mathrm{AP}, \mathrm{Pl}, \mathrm{PP})$ & 90.7 & Consensus \\
\hline
\end{tabular}


Table 2 Common respiratory manifestations by PID type (Continued)

\begin{tabular}{llll}
\hline Common respiratory manifestations by PID type & $\mathrm{N}$ (Composition of panel) & Votes in agreement (\%) & Degree of agreement \\
\hline Recurrent bronchitis & 43 (Al, AP, Pl, PP) & 65.1 & Majority \\
Idiopathic bronchiectasis & 43 (Al, AP, PI, PP) & 72.1 & Majority \\
Recurrent pneumonias* & 43 (Al, AP, Pl, PP) & 83.7 & Consensus \\
Repeated pneumonia in child & $43(\mathrm{Al}, \mathrm{AP}, \mathrm{Pl}, \mathrm{PP})$ & 83.7 & Consensus \\
Chronic bronchial infection & $43(\mathrm{Al}, \mathrm{AP}, \mathrm{Pl}, \mathrm{PP})$ & 67.4 & Majority \\
Autoinflammatory disease & & & Unanimity \\
Recurrent serositis & $43(\mathrm{Al}, \mathrm{AP}, \mathrm{Pl}, \mathrm{PP})$ & 100.0 & \\
\hline
\end{tabular}

Al: adult immunologists; AP: adult pulmonologists; PI: pediatric immunologists; PID: primary immunodeficiency disease; PP: pediatric pulmonologists

* One pneumonia per year for more than one year

warning signs alone (signature signs) as opportunistic infections, or high burden of infection should lead to the referral of the patient to a higher level of care, so that the appropriate tests could be performed.

With regard to tests that are specifically "pulmonary" in a patient with suspected PID, tests adapted to the disease and based on the clinical history are recommended: this is the case for lung function tests and high-resolution computed tomography (HRCT) to evaluate the lung structure, sputum cultures to detect respiratory infections, and sputum cell counts (neutrophils and eosinophils), among others [31]. Chest X-rays may be valuable in acute processes but they are of little use for demonstrating the presence of bronchiectasis or non-infectious pulmonary complications [32, 33]. The sensitivity of lung function tests for the early detection of complications, such as bronchiectasis, is low, and they should always include, if possible, the evaluation of diffusing capacity of the lung for carbon monoxide (DLCO). HRCT, on the other hand, is highly sensitive and specific, and has an important role in the multidisciplinary approach to these conditions, and in the detection, characterization, and quantification of the degree of lung damage, the treatment plan, and follow-up of patients. It is currently the gold standard for the detection and characterization of bronchiectasis $[14,16]$.

Tables 4 and 5 include immunological and pulmonary tests, respectively, that must be performed when PID is suspected, divided into levels of care. Even though, in the last years the use of next-generation sequencing has become an essential route for diagnosing PID and it is usually performed earlier in the diagnostic algorithm of a patient with suspected PID. Meanwhile, protein and functional testing remain to be tested in reference centers if available. Although all the immunological tests (Table 4) reached consensus, some interesting proposals that the authors agreed to include outside of the table are provided. These include protein expression and genetic studies in the third level for phagocyte deficiencies; determination of IgD levels, C-reactive protein (CRP), erythrocyte sedimentation rate (ESR) in the baseline level for autoinflammatory diseases; serial determination of mevalonate in urine during the acute episode in the second level for autoinflammatory diseases; and replacement of tetanus serologies with tetanus/diphtheria. Pulmonary tests (Table 5) were divided into

Table 3 Most common extrapulmonary manifestations of PID (adapted from JC Aldave, JFM) [27]

\begin{tabular}{|c|c|c|c|}
\hline MOST COMMON EXTRAPULMONARY MANIFESTATIONS OF PID & N (Composition of panel) & Votes in agreement (\%) & Degree of agreement \\
\hline Recurrent or complicated sinusitis & $43(\mathrm{Al}, \mathrm{AP}, \mathrm{Pl}, \mathrm{PP})$ & 100.0 & Unanimity \\
\hline Recurrent or complicated otitis & $43(\mathrm{Al}, \mathrm{AP}, \mathrm{Pl}, \mathrm{PP})$ & 93.0 & Consensus \\
\hline Other extrapulmonary infections requiring admission & $43(\mathrm{Al}, \mathrm{AP}, \mathrm{Pl}, \mathrm{PP})$ & 88.4 & Consensus \\
\hline Ectodermal dysplasia & $43(\mathrm{Al}, \mathrm{AP}, \mathrm{Pl}, \mathrm{PP})$ & 72.1 & Majority \\
\hline Chronic diarrhea or malabsorption & $43(\mathrm{Al}, \mathrm{AP}, \mathrm{Pl}, \mathrm{PP})$ & 93.0 & Consensus \\
\hline Difficult-to-treat giardiasis & $43(\mathrm{Al}, \mathrm{AP}, \mathrm{Pl}, \mathrm{PP})$ & 93.0 & Consensus \\
\hline Autoimmune cytopenias or other autoimmunity & $43(\mathrm{Al}, \mathrm{AP}, \mathrm{Pl}, \mathrm{PP})$ & 93.0 & Consensus \\
\hline Lymphadenopathies and hepatosplenomegaly & $43(\mathrm{Al}, \mathrm{AP}, \mathrm{Pl}, \mathrm{PP})$ & 97.7 & Consensus \\
\hline Related cancers, especially associated with viruses & $43(\mathrm{Al}, \mathrm{AP}, \mathrm{Pl}, \mathrm{PP})$ & 83.7 & Consensus \\
\hline Family history of ID or consistent manifestations & $43(\mathrm{Al}, \mathrm{AP}, \mathrm{Pl}, \mathrm{PP})$ & 88.4 & Consensus \\
\hline Post-vaccinal infections & $43(\mathrm{Al}, \mathrm{AP}, \mathrm{Pl}, \mathrm{PP})$ & 79.1 & Majority \\
\hline
\end{tabular}

Al: adult immunologists; AP: adult pulmonologists; ID: immunodeficiency; PI: pediatric immunologists; PID: primary immunodeficiency disease; PP: pediatric pulmonologists 


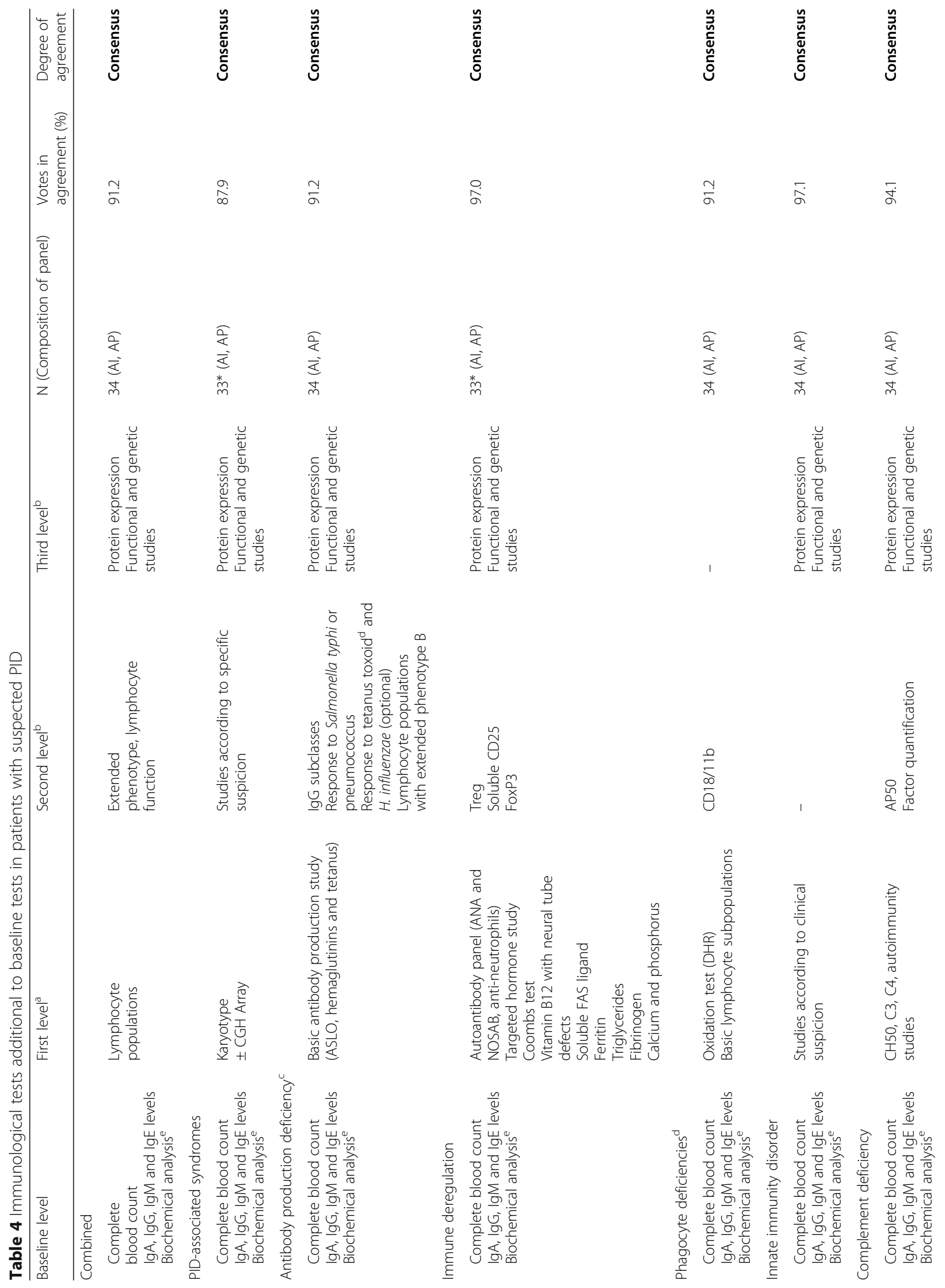




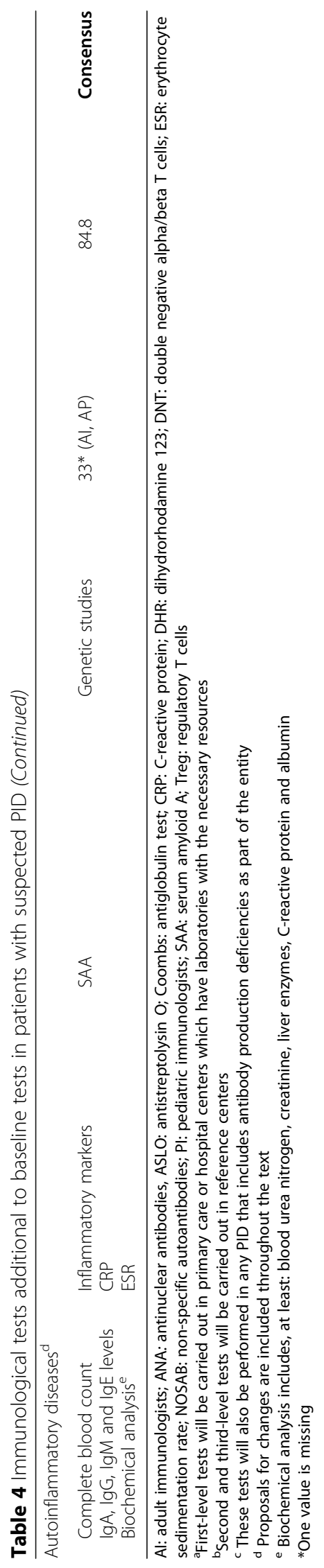




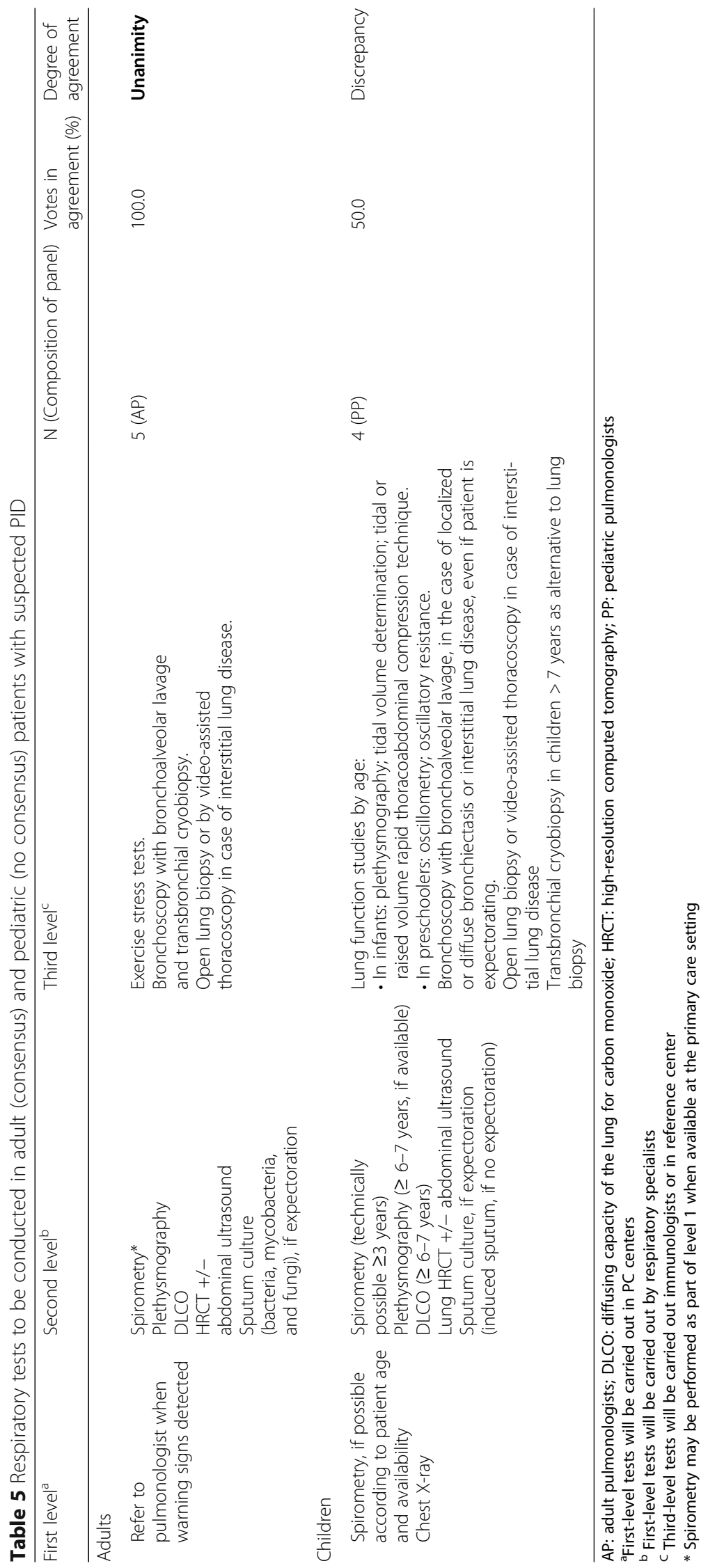


Table 6 Minimum tests to be performed during monitoring of the patient with PID and respiratory symptoms

\begin{tabular}{|c|c|c|c|}
\hline TESTS & $\mathrm{N}$ (Composition of panel) & $\begin{array}{l}\text { Votes in } \\
\text { agreement (\%) }\end{array}$ & $\begin{array}{l}\text { Degree of } \\
\text { agreement }\end{array}$ \\
\hline Patient visit every 6-12 months. & $34(\mathrm{Al}, \mathrm{AP})$ & 91.2 & Consensus \\
\hline $\begin{array}{l}\text { Immunological studies (complete blood count, biochemistry with LDH and Igs) } \\
\text { every 6-12 months. }\end{array}$ & $34(\mathrm{Al}, \mathrm{AP})$ & 91.2 & Consensus \\
\hline $\begin{array}{l}\text { In the event of RT with gammaglobulins, IgG trough values must be measured more } \\
\text { frequently, at least during dose adjustment. }\end{array}$ & $34(\mathrm{Al}, \mathrm{AP})$ & 100.0 & Unanimity \\
\hline $\begin{array}{l}\text { Respiratory tests: } \\
\text { - Annual lung function tests are recommended every year. } \\
\text { - Spirometry must be performed every } 4-6 \text { months in the absence of lung disease. } \\
\text { - The sputum culture must be performed at each visit if patient is expectorating and } \\
\text { in case of any exacerbation. }\end{array}$ & $9(\mathrm{AP}, \mathrm{PP})$ & 100.0 & Unanimity \\
\hline $\begin{array}{l}\text { Lung } C T \text { every } 2-3 \text { years if the patient has pulmonary involvement and every } 5 \text { years } \\
\text { otherwise. Radiation must be minimized in case of radiosensitive ID. }\end{array}$ & $9(\mathrm{AP}, \mathrm{PP})$ & 100.0 & Unanimity \\
\hline $\begin{array}{l}\text { Extrapulmonary tests should be performed according to the patient's symptoms or } \\
\text { manifestations. }\end{array}$ & $43(\mathrm{Al}, \mathrm{Pl}, \mathrm{AP}, \mathrm{PP})$ & 97.7 & Consensus \\
\hline
\end{tabular}

Al: adult immunologists; AP: adult pulmonologists; ID: immunodeficiency; Ig: immunoglobulins; LDH: lactate dehydrogenase; PI: pediatric immunologists; PID: primary immunodeficiency disease; PP: pediatric pulmonologists; RT: replacement therapy

adults and children. Discrepancies emerged regarding the use of these tests in children, so they could not be validated.

\section{Immunoglobulin replacement therapy in PID}

Immunoglobulin replacement therapy (IGRT) is essential in patients with PIDs that directly affect B cell function and antibody production, primarily in severe cases, but also in patients in whom involvement is not obvious from routine testing [34]. IGRT has brought about a significant change in the prognosis of patients with PID. The mortality of CVID has fallen from 29\% in 1971 (before the introduction of intravenous Ig) to $19.6 \%$ in 2012 [35]. In pulmonary complications of PID, IGRT has halved the number of bacterial pneumonias [36]; however, this treatment does not appear to improve other recurrent respiratory infections [36].

There are currently 6 PID phenotypes for which IGRT is indicated or may be indicated [37]: agammaglobulinemia due to the absence of $\mathrm{B}$ cells; hypogammaglobulinemia with impaired specific antibody production; selective antibody deficiencies (IGRT use must be individually evaluated); hypogammaglobulinemia with normal-quality antibody response; isolated deficiency of an IgG subclass with recurrent infections; and recurrent infections due to an unknown immune mechanism.

Since IGRT was introduced in the 1980s, the administered dose of Ig has been gradually increased to achieve higher IgG plasma concentrations [38]. For example, in the case of patients with CVID, IgG plasma concentrations to prevent bacterial infections may range between 5 and $17 \mathrm{~g} / \mathrm{L}$, although trough concentrations of IgG of around $8-10 \mathrm{~g} / \mathrm{L}$ are often recommended. These levels can be achieved with a dose range of $0.2-1.2 \mathrm{~g} / \mathrm{kg} /$ month. Doses must be individualized, and higher doses are required in patients with bronchiectasis and those with certain phenotypes [38].

IGRT can be administered by 2 routes: subcutaneous (SCIG) and intravenous (IVIG); the muscular route has fallen into disuse. There is also a facilitated SCIG which improves its bioavailability and allows infusions every 3 4 weeks [39]. Adequate doses administered by both routes provide physiological IgG concentrations [40, 41], although the kinetics are different: intravenous administration produces a rapid increase in IgG plasma concentrations, while subcutaneous administration produces more gradual increases in plasma levels [41, 42] and more stable serum concentrations [40, 43]. SCIG can be particularly beneficial in patients with low IgG concentrations despite intravenous treatment, since higher mean serum values can be achieved with lower doses of immunoglobulin [44-46]. Both routes of administration have shown equivalence in terms of efficacy and safety $[37,45,47]$, although the incidence of serious systemic adverse effects is higher with IVIG and more mild local effects are observed with SCIG [42, 45, 48].

Different factors must be considered when selecting the route of administration, as not all patients benefit equally from both [49]. Firstly, SCIG is associated with a better quality of life for both patients and their caregivers [46, 50, 51]. A review of 25 studies showed improved health-related quality of life in patients who switched IVIG administration in the hospital for home-administered SCIG [45]. This same review also concluded that SCIG therapy was more cost-effective, mainly due to the reduction in days missed from school or work [45]. The subcutaneous route is also more appropriate for patients with difficulties for venous access, and does not appear to adversely affect renal function [37, 41]. However, the patient must be trained, and the 
equipment and infrastructure required for correct administration may not be easily achieved for all patients. Finally, patient preferences are fundamental when decisions are being made. Multidisciplinary long-term monitoring programs must be implemented that are flexible regarding the alternate use of both routes, depending on the life circumstances of each patient [52, 53]. Despite all, the decision of which route and location of therapy is best may change with age and personal circumstances and requires ongoing re-evaluation; however patients who are stable and managing well with a specific route should not be swapped onto different products for non-clinical reasons.

\section{Monitoring PID patients with pulmonary involvement}

Survival and quality of life of patients with certain PIDs has improved significantly in recent years, particularly as a result of better diagnosis and treatment of infections and other comorbidities, the development of highly potent antimicrobial agents, and the development of specific therapeutic alternatives, such as IgG and others [54]. However, we must not allow the reduction in the number of infections and hospitalizations to generate a lower perception of severity that might lead to a relaxation in the regular clinical monitoring of the disease [9].

The decision on the frequency of evaluations of PID patients depends on several factors, including the type of PID, clinical conditions, and age. There is currently no internationally agreed consensus on the follow-up of patients with PID and lung involvement, but it has been suggested that patients should be evaluated at least once every 6-12 months with a full clinical history and physical examination [9]. Whenever possible, this evaluation should be performed by an expert in PID [55].

The literature reviewed proposes that the follow-up of patients with pulmonary complications should include serial lung function tests and imaging studies, along with regular sputum cultures $[9,56]$. Chest X-ray will only be indicated if acute pulmonary involvement is suspected. It is recommended that HRCTs are performed every 35 years in patients under treatment, depending on their clinical stability [57].

Table 6 sets out the recommendations on the minimum tests to be performed during the clinical monitoring of the PID patient with pulmonary symptoms.

\section{Conclusions}

This study is the first to focus on PID from a pulmonary point of view, addressing the diagnosis, treatment and follow-up of both adult and pediatric patients, while simultaneously including the opinion and clinical experience of more than 40 experts from different fields and specialties who regularly treat these deficiencies. This document is intended to be a useful tool for both primary care professionals and specialists who are treating patients with lung disease, helping them to identify the warning signs of PID in order to make an early diagnosis or else to refer the patient to a specialized unit, thus avoiding unnecessary complications. Other approaches that may help an early identification of PIDs should include education and awareness for specialists. Finally, future possible shortcomings of the study will involve other medical specialties and other clinical manifestations of IDs.

\begin{abstract}
Abbreviations
Al: Adult immunologists; ANA: Antinuclear antibodies; AP: Adult pulmonologists; ASLO: Antistreptolysin O; CG: Calculated globulin; COOMBS: Antiglobulin test; CRP: C-reactive protein; CVID: Common variable immunodeficiency; DHR: Dihydrorhodamine 123; DLCO: Diffusing capacity of the lung; DNT: Double negative alpha/beta T cells; ESR: Erythrocyte sedimentation rate; HRCT: High-resolution computed tomography; ID: Immunodeficiency; Ig: Immunoglobulins; IGRT: Immunoglobulin replacement therapy; ILD: Interstitial lung disease; IUIS: International Union of Immunological Societies; IVIG: Intravenous Ig; JMF: Jeffrey Modell Foundation; KREC: Kappa-deleting element recombination circles; LDH: Lactate dehydrogenase; NOSAB: Non-organ-specific autoantibodies; NSIP: Nonspecific interstitial pneumonia; PC: Primary care; PI: Pediatric immunologists; PID: Primary immunodeficiency disease; PP: Pediatric pulmonologists; RT: Replacement therapy; SAA: Serum amyloid A; SCIG: Subcutaneous Ig; SID: Secondary immunodeficiency diseases; TREC: T-cell recombination excision circles; Treg: Regulatory T cells
\end{abstract}

\section{Acknowledgements}

The authors of this work would like to thank CSL Behring for the financial support provided for the conduct of this study, the ID-Signal Group for their participation as members of the external panel, and Cristina Valiente and Verónica Albert of GOC Networking, for their methodological support throughout the course of the study.

The Lung ID-Signal Group consists of the following members: Óscar Asensio, Luis Allende, Laia Alsina, Ana María Bielsa, Luis Borderías, Sara Calleja-Antolín, Carmen Cámara, Javier Carbone, Carmen Carreras, Francisco Casas, Ana De Andrés, Angela Deyá, Romina Dieli, Amparo Escribano, Luis Fernández-Pereira, José Ma García Ruiz de Morales, Juana Gil-Herrera, Manel Juan, Pilar Llobet, Marcos López-Hoyos, M. Carmen Luna-Paredes, Andrea Martín-Nalda, Mónica Martínez, Josefa Melero, Ana Méndez-Echevarría, Pedro Moral, Antonio Moreno, Olaf Neth, María Núñez, Gonzalo Ocejo-Vinyals, Juliana Ochoa-Grullón, Peter Olbrich, Ricardo Pujol, Daniel Pleguezuelo, Eva Polverino, Jaime Pons, Esther Quintana-Gallego, José Tomás Ramos, Carmen Rodríguez, Juan Luis SantosPérez, M. Elena Seoane, Montserrat Vendrell and Alexandru Vlagea.

\section{Availability of data and material}

The datasets used and/or analyzed during the current study are available from the corresponding author on reasonable request.

\section{Funding}

This study was funded by CSL Behring.

\section{Authors' contributions}

PSP made substantial contributions to the conception and design of the document, to the first draft of the document (before the evaluation of the external panel of experts), and also to the analysis and interpretation of data from the external panel of experts; he has also been involved in drafting and revising the manuscript critically for important intellectual content and has given final approval of the version to be published. JG made contributions the first draft of the document (before the evaluation of the external panel of experts) and to the interpretation of data from the external panel of experts; he also has been involved in revising the manuscript and has given final approval of the version to be published. LIG made contributions the first draft of the document (before the evaluation of the external panel of experts) and to interpretation of data from the external panel of experts; he 
also has been involved in revising the manuscript and has given final approval of the version to be published. CM made contributions the first draft of the document (before the evaluation of the external panel of experts) and to interpretation of data from the external panel of experts; he also has been involved in revising the manuscript and has given final approval of the version to be published. CR made contributions to the first draft of the document (before the evaluation of the external panel of experts) and to the interpretation of data from the external panel of experts; he also has been involved in revising the manuscript and has given final approval of the version to be published. SSR made substantial contributions to the conception and design of the document, to the first draft of the document (before the evaluation of the external panel of experts), and also to the analysis and interpretation of data from the external panel of experts; he also has been involved in drafting and revising the manuscript critically for important intellectual content and has given final approval of the version to be published

\section{Ethics approval and consent to participate}

Not applicable.

\section{Consent for publication}

Not applicable.

\section{Competing interests}

- PSP reports receiving personal fees from CSL Behring and grants from the Jeffrey Modell Foundation during the conduct of the study; and personal fees from Shire SL, and from Grifols, outside the context of the submitted work.

- JG reports receiving personal fees from CLS Berhing, from the Fundación Victor Griffols, and from Shire SL, outside the context of the submitted work.

- LIG reports receiving grants from Fondo de Investigación Sanitaria Carlos III and from Shire SL, and grants and personal fees from CSL Behring, during the conduct of the study.

- CM reports receiving personal fees from CSL Behring, outside the context of the submitted work

- CR reports receiving personal fees from CSL Behring, during the conduct of the study.

- SSR has served as speaker, consultant and advisory member for or has received research funding from CSL Behring, Grifols, Shire and Octapharma.

\section{Publisher's Note}

Springer Nature remains neutral with regard to jurisdictional claims in published maps and institutional affiliations.

\section{Author details}

${ }^{1}$ Hospital U. Vall d'Hebron, P. de la Vall d'Hebron, 119-129, 08035 Barcelona, Spain. ${ }^{2}$ Hospital U. 12 Octubre, Av. Cordoba, s/n, 28041 Madrid, Spain. ${ }^{3}$ Hospital U. Miguel Servet, P. Isabel la Católica, 1-3, 50009 Zaragoza, Spain. ${ }^{4} \mathrm{H}$. Son Espases, C. de Valldemossa, 79, 07120 Palma, Balearic Islands, Spain. ${ }^{5}$ Hospital Clínico San Carlos, C. del Prof Martín Lagos, s/n, 28040 Madrid, Spain. ${ }^{6}$ Hospital Universitari Vall d'Hebron - Institut de Recerca, Barcelona, Spain.
}

Received: 16 July 2018 Accepted: 25 October 2018 Published online: 12 November 2018

\section{References}

1. de Vries E. European Society for Immunodeficiencies m. patient-centred screening for primary immunodeficiency, a multi-stage diagnostic protocol designed for non-immunologists: 2011 update. Clin Exp Immunol. 2012;167: 108-19.

2. Picard C, Bobby Gaspar H, Al-Herz W, et al. International Union of Immunological Societies: 2017 primary immunodeficiency diseases committee report on inborn errors of immunity. J Clin Immunol. 2018;38: 96-128.

3. Costa-Carvalho BT, Grumach AS, Franco $J \mathrm{~L}$, et al. Attending to warning signs of primary immunodeficiency diseases across the range of clinical practice. $J$ Clin Immunol. 2014;34:10-22.
4. Mahlaoui N, Gathmann B, Kindle G, EhI S. ESID registry working party steering committee, ESID society. The European Society for Immunodeficiencies (ESID) registry: recent advancements in the epidemiology of primary Immunodeficiencies and how does that translate in clinical care. Int J Public Health. 2014;1:25-7.

5. Bousfiha AA, Jeddane $L$, Ailal F, et al. Primary immunodeficiency diseases worldwide: more common than generally thought. J Clin Immunol. 2013;33:1-7.

6. Kobrynski L, Powell RW, Bowen S. Prevalence and morbidity of primary immunodeficiency diseases, United States 2001-2007. J Clin Immunol. 2014; 34:954-61.

7. Plebani A, Soresina A, Rondelli R, et al. Clinical, immunological, and molecular analysis in a large cohort of patients with X-linked agammaglobulinemia: an Italian multicenter study. Clin Immunol. 2002;104: 221-30.

8. Modell V, Gee B, Lewis DB, et al. Global study of primary immunodeficiency diseases (PI)--diagnosis, treatment, and economic impact: an updated report from the Jeffrey Modell Foundation. Immunol Res. 2011;51:61-70.

9. Roxo Junior P. Primary immunodeficiency diseases: relevant aspects for pulmonologists. Jornal brasileiro de pneumologia : publicacao oficial da Sociedade Brasileira de Pneumologia e Tisilogia. 2009;35:1008-17.

10. Jesenak M, Banovcin P, Jesenakova B, Babusikova E. Pulmonary manifestations of primary immunodeficiency disorders in children. Front Pediatr. 2014;2:77.

11. Jeffrey Modell Foundation. 10 Warning Signs of Primary Immunodeficiency for Adults. Disponible en: http://www.info4pi.org/aboutPl/pdf/ Adult10WarningSigns-FINAL.pdf.

12. Arkwright PD, Gennery AR. Ten warning signs of primary immunodeficiency: a new paradigm is needed for the 21st century. Ann N Y Acad Sci. 2011; 1238:7-14.

13. Subbarayan A, Colarusso G, Hughes SM, et al. Clinical features that identify children with primary immunodeficiency diseases. Pediatrics. 2011;127:810-6.

14. Hampson FA, Chandra A, Screaton NJ, et al. Respiratory disease in common variable immunodeficiency and other primary immunodeficiency disorders. Clin Radiol. 2012;67:587-95.

15. Verma N, Grimbacher B, Hurst JR. Lung disease in primary antibody deficiency. Lancet Respir Med. 2015;3:651-60.

16. Baumann $U$, Routes JM, Soler-Palacín P, Jolles $S$. The lung in primary Immunodeficiencies: new concepts in infection and inflammation. Front Immunol. 2018;9:1837.

17. Serra G, Milito C, Mitrevski M, et al. Lung MRI as a possible alternative to CT scan for patients with primary immune deficiencies and increased radiosensitivity. Chest. 2011;140:1581-9.

18. Fried AJ, Bonilla FA. Pathogenesis, diagnosis, and management of primary antibody deficiencies and infections. Clin Microbiol Rev. 2009;22:396-414.

19. Nonas S. Pulmonary manifestations of primary immunodeficiency disorders. Immunol Allergy Clin N Am. 2015;35:753-66.

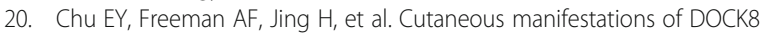
deficiency syndrome. Arch Dermatol. 2012;148:79-84.

21. Zhang Q, Davis JC, Lamborn IT, et al. Combined immunodeficiency associated with DOCK8 mutations. N Engl J Med. 2009;361:2046-55.

22. Al-Herz W, Nanda A. Skin manifestations in primary immunodeficient children. Pediatr Dermatol. 2011;28:494-501.

23. Kobrynski LJ, Mayer L. Diagnosis and treatment of primary immunodeficiency disease in patients with gastrointestinal symptoms. Clin Immunol. 2011;139:238-48.

24. Cunningham-Rundles $C$. Autoimmunity in primary immune deficiency: taking lessons from our patients. Clin Exp Immunol 2011;164 Suppl 2:6-11.

25. Moraes-Vasconcelos D, Costa-Carvalho BT, Torgerson TR, Ochs HD. Primary immune deficiency disorders presenting as autoimmune diseases: IPEX and APECED. J Clin Immunol. 2008;28(Suppl 1):S11-9.

26. Arason GJ, Jorgensen GH, Ludviksson BR. Primary immunodeficiency and autoimmunity: lessons from human diseases. Scand J Immunol. 2010;71: 317-28.

27. Warning signs of Primary Immunodeficiency for specialty care physicians. (Accessed Sept.-19-2018, at http://downloads.info4pi.org/pdfs/DiagnosticAlgorithm-for-Specialty-Care-Physicians.pdf.)

28. Jolles S, Borrell R, Zouwail S, et al. Calculated globulin (CG) as a screening test for antibody deficiency. Clin Exp Immunol. 2014;177:671-8.

29. Pecoraro A, Jolles S, Crescenzi L, et al. Validation of calculated globulin (CG) as a screening test for antibody deficiency in an Italian University hospital. Curr Pharm Biotechnol. 2018. 
30. Garcia-Prat M, Vila-Pijoan G, Martos Gutierrez S, et al. Age-specific pediatric reference ranges for immunoglobulins and complement proteins on the Optilite. J Clin Lab Anal. 2018:e22420.

31. Ozerovitch L. Primary immune deficiency in bronchiectasis. Nurs Times. 2016;112:16-9

32. Thickett KM, Kumararatne DS, Banerjee AK, Dudley R, Stableforth DE Common variable immune deficiency: respiratory manifestations, pulmonary function and high-resolution CT scan findings. QJM. 2002;95: 655-62.

33. Sala Cunill A, Soler-Palacín P, Martín De Vicente C, Labrador Horrillo M, Luengo Sánchez O, Figueras Nadal C. Common variable immunodeficiency. Prognostic factors for lung damage Med Clin (Barc). 2010;134:64-7.

34. Perez EE, Orange JS, Bonilla F, et al. Update on the use of immunoglobulin in human disease: a review of evidence. J Allergy Clin Immunol. 2017;139: S1-s46.

35. Resnick ES, Moshier EL, Godbold JH, Cunningham-Rundles C. Morbidity and mortality in common variable immune deficiency over 4 decades. Blood. 2012;119:1650-7.

36. Jolles S. Subclinical infection and dosing in primary immunodeficiencies. Clin Exp Immunol. 2014;178(Suppl 1):67-9.

37. Stiehm ER, Orange JS, Ballow M, Lehman H. Therapeutic use of immunoglobulins. Adv Pediatr Infect Dis. 2010;57:185-218.

38. Lucas M, Lee M, Lortan J, Lopez-Granados E, Misbah S, Chapel H. Infection outcomes in patients with common variable immunodeficiency disorders: relationship to immunoglobulin therapy over 22 years. J Allergy Clin Immunol 2010;125:1354-1360 e4.

39. Wasserman RL. Overview of recombinant human hyaluronidase-facilitated subcutaneous infusion of lgG in primary immunodeficiencies. Immunotherapy. 2014;6:553-67.

40. Berger M. Subcutaneous administration of IgG. Immunol Allergy Clin N Am. 2008;28:779-802 viii.

41. Gardulf A. Immunoglobulin treatment for primary antibody deficiencies: advantages of the subcutaneous route. BioDrugs. 2007;21:105-16.

42. Haddad É, Barnes D, Kafal A. Home therapy with subcutaneous immunoglobulins for patients with primary immunodeficiency diseases. Transfus Apher Sci. 2012:46:315-21.

43. Gaspar J, Gerritsen B, Jones A. Immunoglobulin replacement treatment by rapid subcutaneous infusion. Arch Dis Child. 1998;79:48-51.

44. Thépot S, Malphettes M, Gardeur A, et al. Immunoglobulin dosage and switch from intravenous to subcutaneous immunoglobulin replacement therapy in patients with primary hypogammaglobulinemia: decreasing dosage does not alter serum IgG levels. J Clin Immunol. 2010;30:602-6.

45. Lingman-Framme J, Fasth A. Subcutaneous immunoglobulin for primary and secondary immunodeficiencies: an evidence-based review. Drugs. 2013; 73:1307-19.

46. Berger M, Murphy E, Riley P, Bergman GE, Investigators VT. Improved quality of life, immunoglobulin $\mathrm{G}$ levels, and infection rates in patients with primary immunodeficiency diseases during self-treatment with subcutaneous immunoglobulin G. South Med J. 2010;103:856-63.

47. Gardulf A, Nicolay U, Asensio O, et al. Rapid subcutaneous IgG replacement therapy is effective and safe in children and adults with primary immunodeficiencies--a prospective, multi-national study. J Clin Immunol. 2006;26:177-85.

48. Jiang F, Torgerson TR, Ayars AG. Health-related quality of life in patients with primary immunodeficiency disease. Allergy Asthma Clin Immunol. 2015;11:27.

49. Jolles S, Orange JS, Gardulf A, et al. Current treatment options with immunoglobulin $\mathrm{G}$ for the individualization of care in patients with primary immunodeficiency disease. Clin Exp Immunol. 2015;179:146-60.

50. Gardulf A, Nicolay U, Math D, et al. Children and adults with primary antibody deficiencies gain quality of life by subcutaneous IgG self-infusions at home. J Allergy Clin Immunol. 2004;114:936-42.

51. Misbah S, Sturzenegger MH, Borte M, et al. Subcutaneous immunoglobulin: opportunities and outlook. Clin Exp Immunol. 2009;158(Suppl 1):51-9.

52. Bourdin A, Berger J, Früh A, Spertini F, Bugnon O. Subcutaneous immunoglobulin and support program: what level of interest of patients? Rev Med Suisse. 2015;11:831-5.

53. Soler-Palacín P, Gasó-Gago I, Fernández-Polo A, et al. Intravenous and subcutaneous immunoglobulin replacement: a two-way road. Optimizing healthcare quality in patients with primary immunodeficiencies. J Clin Immunol. 2014;34:1015-7.
54. Chinen J, Anmuth D, Franklin AR, Shearer WT. Long-term follow-up of patients with primary immunodeficiencies. J Allergy Clin Immunol. 2007;120: 795-7.

55. Bonilla FA, Bernstein IL, Khan DA, et al. Practice parameter for the diagnosis and management of primary immunodeficiency. Ann Allergy Asthma Immunol. 2005;94:S1-63.

56. Tarzi MD, Grigoriadou S, Carr SB, Kuitert LM, Longhurst HJ. Clinical immunology review series: an approach to the management of pulmonary disease in primary antibody deficiency. Clin Exp Immunol. 2009;155:147-55.

57. Jolles S, Sánchez-Ramón S, Quinti l, et al. Screening protocols to monitor respiratory status in primary immunodeficiency disease: findings from a European survey and subclinical infection working group. Clin Exp Immunol. 2017;190:226-34.

\section{Ready to submit your research? Choose BMC and benefit from:}

- fast, convenient online submission

- thorough peer review by experienced researchers in your field

- rapid publication on acceptance

- support for research data, including large and complex data types

- gold Open Access which fosters wider collaboration and increased citations

- maximum visibility for your research: over $100 \mathrm{M}$ website views per year

At BMC, research is always in progress.

Learn more biomedcentral.com/submissions 